\title{
Environmental Conditions and Psychophysiological Response of Pilots and Flight Attendants in Commercial Long-Haul Flights
}

\author{
Michael Trimmel $^{*}$
}

Medical University of Vienna, Kinderspitalgasse 15, A-1095 Vienna, Austria

\begin{abstract}
The impact of environmental conditions as found in aircraft on pilots and flight attendants was investigated by the EU-project HEACE. Measurements of 6 long-haul rotations, three Vienna-Delhi (7-h flights) and three ViennaTokyo (12-h flights with a rest of 3 hours for the crew during flights), were investigated in cooperation with Austrian Airlines on board of aircraft of the Airbus type. Besides the recordings of environmental conditions (air temperature, relative humidity, sound pressure level), also physiological measures and ratings were collected on 12 flights in 13 pilots and 64 flight attendants. The electrocardiogram was recorded continuously, BP, SpO2, and ratings (tiredness, health symptoms) were collected as spot measurements up to three times during flights and as baseline measures for which also heart rate (HR) and heart rate variability (pNN50) was computed. Analyses showed a great variety in environmental conditions and human response depending on flight duration, destination, area in aircraft, and task demands. Extreme observations include a temperature range from $18.5-27.7^{\circ} \mathrm{C}, 0 \% \mathrm{RH}$ in the cockpit, $88 \mathrm{~dB}(\mathrm{~B})$ in the rear of aircraft, $\mathrm{HR}$ of $135 \mathrm{during}$ service, and $50 \%$ of $\mathrm{SpO} 2$ measures in pilots during cruising were $\leq 94 \%$ oxygen saturation. Ratings of dry eyes/skin symptoms and tiredness are increased with flight duration. Results indicate that mean values reflect only very small aspects of the diversity in flight conditions and human response.
\end{abstract}

Keywords: Aviation, high altitude, environment, heart rate, heart rate variability, oxygen saturation, alertness, noise, humidity.

\section{INTRODUCTION}

Working conditions on board of an aircraft are still an issue of interest. On the one hand, the environmental condition of the aircraft cabin is in some ways similar to that of other indoor environments, such as homes and offices, in the way that people are exposed to a mixture of outside and recirculated air. But on the other hand, however, the cabin environment is different from other indoor environments in many respects, i.e., the high occupant density, the impossibility of occupants to leave at will, and the need for depressurization. Thus, in flight, people encounter a combination of environmental factors that include low humidity, reduced air pressure, and potential exposure to air contaminants, such as ozone (O3), carbon monoxide (CO), various organic chemicals and biological agents [1], stress due to noise pollution [2], and flight attendants are exposed to social stress, too [3, 4].

In particular, the impact of reduced air pressure on persons' health and well-being was addressed in recent studies $[5,6]$. Since aircraft are cruising at altitudes of about 39000 $\mathrm{ft}$, this corresponds to an in-cabin pressure equivalent to an altitude of about $6000 \mathrm{ft}$, and is caused by constructional characteristics of the aircraft. Such a lower air pressure (maybe together with the other environmental characteristics) is currently discussed for its implications on comfort and well-being of passengers on board. As a mediating mechanism, the lower oxygen saturation under hypobaric

*Address correspondence to this author at the Medical University of Vienna, Kinderspitalgasse 15, A-1095 Vienna, Austria;

Tel: +436648001634911; Fax: +43142779647;

E-mail: michael.trimmel@meduniwien.ac.at conditions is discussed. All of those non-optimal environmental conditions in aircraft affect, besides passengers, also pilots and flight attendants. Moreover, both occupations are loaded additionally by demands of their specific working conditions, i.e., flight attendants by a high number of social interactions with persons who could be stressed, besides their physical activities in particular during the service phases, and pilots by their demands of flying, navigating, and managing the flight.

As air travel is still growing, the number of persons exposed to cabin environment is rising as well. Airlines are optimizing their travel capacity by facilitating long-haul flights and shorter turnovers. Such an organizational optimization has implications on the load of the crew, with shorter (or even no) periods of adaptation at the target airport, and could possibly affect performance and well-being in particular in subsequent flights. The aim of this study was to get objective information about the response of the human body and some psychological experiences of pilots and flight attendants during real long-haul flights. There are some reports [7] and complaints about the cockpit, in particular about relative air humidity, which varied also by type of aircraft (B767-300, B767-600, DC9/21-41, MD 81/90) and in the cabin [8] with a mean of $5 \%$ relative air humidity during intercontinental flights, but also too high or varying air temperature, stuffy air, noise, and other complaints are reported. However, a parallel investigation measuring environmental conditions and physiological response as well as ratings during the course of long-haul flights will give more insight and was chosen in the present investigation. Moreover, comparing outgoing flights with incoming flights, additional aspects like the effect of resting away from home and effects of jet 
lag may modulate the physiological and psychological responses.

Thus, the present study was undertaken to investigate environmental conditions and the human response of pilots and flight attendants with respect to their area of working in the aircraft, and with respect to a destination without a resting period (Delhi) and one with a resting period during the flight (Tokyo). To assess the response of the autonomic nervous system, the method of recording the electrocardiogram to analyze heart rate and heart rate variability as an indication of physiological load [9, 10] during the whole flight period as well as the time before and after the flight was chosen. Such electrophysiological ambulatory recordings have the advantage of being a real-time indication of the response in the cardiovascular system without disturbing the routine work of the person under investigation [11]. Additionally, spot measurements of oxygen saturation together with ratings on tiredness and on ability to concentrate, as well as ratings on health symptoms were done at particular periods to cover subjective experience of respective flight conditions as well as of time on work.

\section{METHOD AND PROCEDURE}

\section{Flights and Recordings}

In 6 long-haul rotations (12 flights), on three 12h-flights from Vienna to Tokyo and back, and on three 7h-flights from Vienna to Delhi and back, ambulatory psychophysiological recordings were done. From the time before briefing to the time in the hotel of the target airport the electrocardiogram (ECG) was recorded with Physiologger®, a multichannel polygraph. This portable measurement system has the following system components integrated: amplifier, memory, analogue-to-digital converter and a micro-processor module (MedNatic, Rimkus Medizintechnik GmbH, Parsdorf, Germany). The heart rate was recorded from chest wall with standard ECG electrodes.

\section{Spot Measurements}

Spot measurements of blood pressure, oxygen saturation and ratings were done at the time before briefing on the airport and after each service phase during the flights (i.e., twice on the flights Vienna-Delhi-Vienna and 3 times on the flights Vienna-Tokyo-Vienna). Blood pressure was measured with the subjects seated and his/her bare left arm resting on the bent right arm at the level of the heart, with a digital recording sphygmomanometer, equipped with an oscillometric pressure sensor. Blood oxygen saturation was measured with a Nonin 9500 Onyx Digital Finger Pulse Oximeter at the spot measurement periods, and ratings on moods and comfort were collected with paper/pencil questionnaires. Sociodemographic data were gathered by paper/pencil at the time before the first briefing at the Vienna airport.

\section{Subjects}

On the flights Vienna-Delhi-Vienna 2 pilots were in the cockpit and 10 flight attendants were on duty in the cabin (2 refused to take part in the study). On the flights ViennaTokyo-Vienna the flight crew consisted of 3 pilots, with one pilot resting (in a compartment behind the cockpit) from the time of reaching cruising altitude to the time of preparing for landing (i.e., about 3 hours per person), and the crew of flight attendants consisted of 13 persons. Crew rested in the sleeping compartment for about 3 hours in an alternating manner (again from the time of reaching cruising altitude to the time of preparation for landing). Altogether, 156 data sets from $\mathrm{N}=78$ flight attendants and 26 data sets from $\mathrm{N}=$ 13 pilots were collected (see Table 1 for descriptive characteristics of the investigated persons).

\section{Ratings}

Intensity (7-point scale: 1 not at all -7 very severe) of 29 symptoms (01) dry eyes, (02) irritated eyes, (03) watering eyes, (04) stuffy nose, (05) dry nose, (06) runny nose, (07) dry/irritated throat, (08) cough, (09) dry skin/lips, (10) irritated skin, (11) pain in ears/sinuses, (12) dizziness, (13) faintness/light-headedness, (14) lethargy/tiredness, (15) headache, (16) difficulty in concentrating, (17) feeling anxious, (18) stressed, (19) feeling irritable, (20) nausea/feeling sick, (21) other stomach discomfort, (22) difficulty with breathing, (23) flu-like symptoms, (24) swollen or heavy legs/feet, (25) muscle/joint pain in back, (26) muscle/joint pain in neck, (27) other muscle/joint pain, (28) sweating, (29) cold hands as well as tiredness and the ability to concentrate (a 21-point scale with labels on every second mark: 0 not at all, 10 very) were rated at the time of the spot measurements.

\section{Procedure}

The flights were arranged by the Vienna group of the HEACE consortium in cooperation with Austrian Airlines on aircraft of the type Airbus. In preceding security tests, all the equipment was tested for not affecting electronic instruments of the aircraft. Pilots as well as flight attendants were informed that in-flight measurements were to be taken previous to the respective flights. Each person had the option to decline the recordings and each captain had to give his consent to the in-flight measurements for himself and his crew. One pilot on the outgoing flight from Vienna to Delhi and

Table 1. Mean Age (SD, Minimum and Maximum Values) and Number of Pilots and of Flight Attendants Participating in the Study

\begin{tabular}{|c|c|c|c|c|c|c|c|c|c|c|}
\hline$\frac{\text { Destination }}{\text { Age }}$ & \multicolumn{5}{|c|}{ Pilots } & \multicolumn{5}{|c|}{ Flight Attendants } \\
\hline Delhi (D) & 42 & 5 & 10.22 & 32 & 55 & 34 & $28(8)$ & 7.05 & 28 & 59 \\
\hline Tokyo (T) & 40 & 8 & 7.19 & 32 & 49 & 30 & $36(10)$ & 4.14 & 23 & 41 \\
\hline $\mathrm{D}+\mathrm{T}$ & 41 & 13 & 8.10 & 32 & 55 & 32 & $64(18)$ & 5.82 & 23 & 59 \\
\hline
\end{tabular}


one pilot on both the outgoing flight from Vienna to Tokyo and the incoming flight declined the ambulant heart rate monitoring. Nevertheless, they agreed to the collection of spot measurements and supported data collection by filling in questionnaires anyhow. Additionally, some physiological data are missing due to excluding artefacts particularly caused by movement or equipment failure and due to participants being unavailable for testing due to work demands. Thus, the number of participants or measurements will be reported for each analysis separately. Flight attendants' and pilots' extra time for wiring the recording equipment before the flight and dewiring after the flight was compensated monetarily.

After wiring and filling in questionnaires at the time before briefing, the investigators, 3 of the Medical University of Vienna (MUV) responsible for psychophysiology and 3 others of the consortium responsible for environmental measurements, boarded like the other travelers, only earlier, to fix the technical measurement equipment before boarding of the passengers. MUV organized an official airport representative on each airport for the time of boarding and the security checks, who was responsible that the investigators as well as the wired crew could go on board with the technical equipment approved by Austrian Airlines. One psychophysiology investigator was seated in the business class and was responsible for spot measurements of flight attendants in the business class as well as of the pilots. The second psychophysiology investigator responsible for collecting data was seated in the front part of the economy section, and the third in the rear section. After arrival at the destinations, investigators went to the respective hotels together with the crew for dewiring. Then recordings were stored on notebooks, and equipment was prepared for the measurements on the next day on the flights back to Vienna.

Spot measurements during flights were done after the first service was finished (about $2 \mathrm{~h}$ after take off), on the flight to Tokyo after the second service (a snack) and after the service before landing (second service on the Delhi flight, third service on the Tokyo flight). Although the crew was very cooperative, sometimes spot measurements were interrupted by flight demands or passenger demands.

Most of the environmental characteristics were measured continuously during the flight (by UNOL, ITAP, EADS, and Paragon; see the acknowledgement for persons involved in those measurements), but for comparison with spot measurements and with HR and HRV measures for the periods of spot measurements they were averaged for the $15 \mathrm{~min}$ of the spot measurement periods.

\section{Analysis of HR and HRV}

Continuous recordings of ECG were analyzed for epochs of $5 \mathrm{~min}$. For the descriptive measures (as presented in the tables) values were averaged for time periods of 15 min during the time of measuring blood pressure, oxygen saturation, and paper/pencil work, all while seated (except the HR values for the time of service of the flight attendants). About at the same time data from pilots were collected, also while seated. Variables reported here are mean heart rate (HR) and pNN50 as a time domain parameter of HRV that is recommended by the Task Force of the European Society of Cardiology and the North American Society of Pacing Electrophysiology [12].

\section{RESULTS}

\section{Environmental Conditions}

Characteristics of environmental conditions (air temperature, sound pressure level, and relative humidity) for the cockpit, the business class section, as well as the front and rear part of the economy section were computed for outgoing and incoming flights to each destination, as well as for flight phases. Air temperature varied remarkably between flights, phases, and sections in the range from $18.5^{\circ} \mathrm{C}$ to $27.7^{\circ} \mathrm{C}$ (see Table 2 for details). Relative humidity was low in the front part of the aircraft, in particular in the cockpit (with lowest values of $0 \% \mathrm{RH}$ ) and was above $10 \% \mathrm{RH}$ in the rear economy section (see Table 3). Sound pressure levels showed lowest values in the front part and higher values in general, up to $82 \mathrm{~dB}(\mathrm{~A})$ and $88 \mathrm{~dB}(\mathrm{~B})$, in the rear economy section (see Table $\mathbf{4}$ for sound pressure levels).

\section{Ratings}

All statistical analyses were conducted with the program STATISTICA (StatSoft Europe $\mathrm{GmbH}$ ). Factor analysis (principal axis factor analysis with varimax rotation) for symptoms revealed 3 factors (with eigenvalues $>1.0$ ). Factor one (F1) explains $19.4 \%$ of variance and can be interpreted as "unspecific symptoms" with high loadings $(>0.5)$ in the items 12-20 (headache, dizziness, faintness, stressed, etc.). Factor two (F2) explaining $16.3 \%$ of variance can be interpreted as "irritated or dry eyes and skin" with loadings (> 0.5 ) in the items $1,2,5,8,9$, and 10 but also in item 24 (swollen or heavy legs/feet). Factor three (F3) explains $9.0 \%$ of variance and can be interpreted as "pain" with loadings in the items 23, 25, and 26. For further analysis mean values of the items of the factors were computed and analyzed by a 5way $(2 \times 2 \times 4 \times 2 \times 3)$ ANOVA with the independent variables Destination (Delhi vs Tokyo), Incoming vs Outgoing flight, Phase (baseline, phase 1 to 3 , with incomplete cells in phase 3 on the flights to Delhi), Pilots vs. Flight attendants and the (repeated) factors Symptoms $(\mathrm{F} 1-\mathrm{F} 3)$. Results indicated a significant effect for Phase $(F(2,501)=10.15, p<$ $.001)$ and a significant interaction of Symptoms $\mathrm{x}$ Phase $(\mathrm{F}(4,1002)=11.60, \mathrm{p}<.001)$. Mean values and 95\% confidence intervals are presented in Fig. (1), and indicate that severity of symptoms is increasing from baseline to phase 3 and that the symptoms related to irritation and dryness of eyes and skin (F1) became much higher during flight than the factors of unspecific symptoms (F1) and of pain (F3). No effect of destination, incoming versus outgoing flights, or between pilots and flight attendants was observed.

Tiredness and ability to concentrate were analyzed by separate 4-way ANOVAs (with the independent variables Destination (Delhi vs Tokyo), Incoming vs Outgoing flight, Phase (baseline, phase 1 to 3, with incomplete cells in phase 3 on the flights to Delhi), and Pilots vs Flight attendants. ANOVA results for "tiredness" revealed a significant effect only for Phase $(\mathrm{F}(2,497)=12.88, \mathrm{p}<.001)$ with higher values during flight (in particular in phase 2) compared to base- 
Table 2. Mean Values (N, SD, Minimum and Maximum Values) of Air Temperature $\left({ }^{\circ} \mathrm{C}\right)$ in the Cockpit, the Business Section, the Front Part (Economy 1) and the Rear Part of the Economy Section (Economy 2) for Flight Destinations, Flight Phases, and Outgoing and Incoming Flights

\begin{tabular}{|c|c|c|c|c|c|c|c|c|c|c|c|c|c|c|c|c|c|c|c|c|c|c|}
\hline \multirow{2}{*}{$\frac{{ }^{\circ} \mathbf{C}}{\text { Dest. }}$} & \multirow{2}{*}{ Phase } & \multirow{2}{*}{ Dir. } & \multicolumn{5}{|c|}{ Cockpit } & \multicolumn{5}{|c|}{ Business } & \multicolumn{5}{|c|}{ Economy 1} & \multicolumn{5}{|c|}{ Economy 2} \\
\hline & & & $\mathbf{M}$ & $\mathbf{N}$ & SD & Min & $\operatorname{Max}$ & M & $\mathbf{N}$ & SD & Min & $\operatorname{Max}$ & $\mathbf{M}$ & $\mathbf{N}$ & SD & Min & $\operatorname{Max}$ & $\mathbf{M}$ & $\mathbf{N}$ & SD & Min & Max \\
\hline \multirow{4}{*}{ Delhi } & \multirow{2}{*}{ Phase 1} & Out & 22.6 & 3 & 1.29 & 21.1 & 23.6 & 22.1 & 3 & 0.62 & 21.5 & 22.7 & 23.0 & 3 & 2.07 & 20.6 & 24.4 & 22.6 & 3 & 1.44 & 21.5 & 24.2 \\
\hline & & In & 23.5 & 3 & 0.30 & 23.2 & 23.8 & 23.0 & 2 & 0.20 & 22.8 & 23.1 & 23.7 & 3 & 1.34 & 22.2 & 24.7 & 25.1 & 3 & 2.53 & 22.6 & 27.7 \\
\hline & \multirow{2}{*}{ Phase 2} & Out & 23.5 & 3 & 1.52 & 22.1 & 25.1 & 23.9 & 1 & 0.00 & 23.9 & 23.9 & 23.0 & 3 & 1.35 & 21.5 & 24.0 & 22.9 & 3 & 0.70 & 22.3 & 23.6 \\
\hline & & In & 24.4 & 3 & 1.43 & 23.3 & 26.0 & 23.6 & 3 & 0.40 & 23.2 & 24.0 & 22.5 & 3 & 1.14 & 21.5 & 23.7 & 22.9 & 3 & 1.33 & 21.4 & 23.8 \\
\hline \multirow{6}{*}{ Tokyo } & \multirow{2}{*}{ Phase 1} & Out & 22.5 & 2 & 0.07 & 22.5 & 22.6 & 21.1 & 1 & 0.00 & 21.1 & 21.1 & 21.9 & 3 & 0.97 & 20.8 & 22.7 & 22.1 & 3 & 2.22 & 19.6 & 23.7 \\
\hline & & In & 23.9 & 2 & 2.04 & 22.5 & 25.4 & 23.1 & 3 & 2.63 & 21.2 & 26.1 & 23.5 & 3 & 0.39 & 23.2 & 23.9 & 23.1 & 3 & 0.82 & 22.2 & 23.8 \\
\hline & \multirow{2}{*}{ Phase 2} & Out & 23.9 & 2 & 0.66 & 23.4 & 24.4 & 21.6 & 2 & 3.71 & 19.0 & 24.3 & 21.8 & 2 & 0.68 & 21.3 & 22.2 & 21.6 & 3 & 2.71 & 18.5 & 23.4 \\
\hline & & In & 25.1 & 3 & 2.82 & 22.0 & 27.6 & 24.2 & 2 & 2.82 & 22.2 & 26.2 & 23.3 & 3 & 0.90 & 22.3 & 24.0 & 21.6 & 3 & 2.13 & 19.3 & 23.3 \\
\hline & \multirow{2}{*}{ Phase 3} & Out & 23.7 & 2 & 1.37 & 22.8 & 24.7 & 22.0 & 2 & 3.26 & 19.7 & 24.3 & 22.1 & 2 & 1.65 & 20.9 & 23.3 & 21.0 & 2 & 2.61 & 19.2 & 22.9 \\
\hline & & In & 22.9 & 2 & 3.14 & 20.7 & 25.2 & 23.0 & 1 & 0.00 & 23.0 & 23.0 & 22.9 & 3 & 0.21 & 22.7 & 23.1 & 21.3 & 1 & 0.00 & 21.3 & 21.3 \\
\hline
\end{tabular}

Table 3. Mean Values (N, SD, Minimum and Maximum Values) of Relative Humidity (RH) in the Cockpit, the Business Section, the Front Part (Economy 1) and the Rear Part of the Economy Section (Economy 2) for Flight Destinations, Flight Phases, and Outgoing and Incoming Flights

\begin{tabular}{|c|c|c|c|c|c|c|c|c|c|c|c|c|c|c|c|c|c|c|c|c|c|c|}
\hline$\frac{\% \mathrm{RH}}{\text { Dest. }}$ & Phase & \multicolumn{6}{|c|}{ Cockpit } & \multicolumn{5}{|c|}{ Business } & \multicolumn{5}{|c|}{ Economy 1} & \multicolumn{5}{|c|}{ Economy 2} \\
\hline \multirow{3}{*}{ Delhi } & \multirow{2}{*}{ Phase 1} & Out & 6 & 3 & 1.36 & 5 & 8 & 9 & 3 & 1.54 & 8 & 11 & 10 & 3 & 0.47 & 9 & 10 & 10 & 3 & 1.31 & 9 & 12 \\
\hline & & In & 4 & 3 & 2.58 & 1 & 6 & 8 & 1 & 0.00 & 8 & 8 & 11 & 3 & 2.09 & 9 & 14 & 12 & 3 & 2.24 & 10 & 14 \\
\hline & Phase 2 & Out & 5 & 3 & 0.56 & 4 & 6 & 10 & 2 & 1.90 & 9 & 12 & 11 & 3 & 0.61 & 11 & 12 & 10 & 3 & 3.11 & 7 & 14 \\
\hline \multirow{4}{*}{ Tokyo } & \multirow{2}{*}{ Phase 1} & Out & 6 & 2 & 2.05 & 5 & 8 & 10 & 1 & 0.00 & 10 & 10 & 9 & 3 & 1.14 & 8 & 10 & 13 & 2 & 6.33 & 9 & 18 \\
\hline & & In & 7 & 2 & 1.70 & 5 & 8 & 8 & 2 & 0.22 & 8 & 8 & 8 & 2 & 1.25 & 7 & 9 & 11 & 2 & 3.02 & 9 & 13 \\
\hline & \multirow{2}{*}{ Phase 2} & Out & 7 & 2 & 0.47 & 7 & 8 & 9 & 2 & 1.82 & 7 & 10 & 8 & 2 & 0.09 & 8 & 8 & 13 & 1 & 0.00 & 13 & 13 \\
\hline & & In & 5 & 2 & 0.48 & 5 & 6 & 7 & 3 & 2.28 & 5 & 10 & 9 & 3 & 0.89 & 8 & 10 & 12 & 3 & 2.45 & 10 & 14 \\
\hline
\end{tabular}

line (see Fig. 2). However, as indicated by confidence interval, baseline difference between outgoing and incoming flights to/from Tokyo in pilots and flight attendants can be seen, as well as higher values for incoming flights from Delhi for pilots and flight attendants in phase 2. ANOVA for "ability to concentrate" revealed a significant effect only for Phase $(\mathrm{F}(2,479)=4.42, \mathrm{p}<.05)$ with lower values for phase 2 and 3 compared to baseline (see Fig. 3). Confidence intervals for mean values in flight attendants revealed baseline differences between outgoing and incoming flights to/from Tokyo, and differences in phase 2 of outgoing and incoming flights to/from Delhi.

\section{Heart Rate}

From the continuous recordings of the electrocardiogram, mean heart rate (HR) was computed for intervals of 5 minutes. Mean values of 5 min HR intervals for significant epochs (boarding, service, test phases, etc.) of the flights to Tokyo are displayed in Fig. (4). Breakdown of mean HR (15 min epochs) during "service time" (Table 5) showed remarkable ranges of HR in pilots (from $41-103 \mathrm{bpm}$ ) as well as in flight attendants $(43-135 \mathrm{bpm})$. Whereas flight attendants showed a remarkable increase in particular during the first service, in pilots the HR decreased during cruising and 
Table 4. Mean Values (N, SD, Minimum and Maximum Values) of Sound Pressure Level (SPL) A-Weighted [dB(A)] in the Top Part and B-Weighted [dB(B)] in the Lower Part of the Table, in the Cockpit, the Business Section, the Front Part (Economy 1) and the Rear Part of the Economy Section (Economy 2) for Flight Destinations, Flight Phases, and Outgoing and Incoming Flights

\begin{tabular}{|c|c|c|c|c|c|c|c|c|c|c|c|c|c|c|c|c|c|c|c|c|c|c|}
\hline $\begin{array}{l}\mathrm{dB}(\mathrm{A}) \\
\text { Dest. }\end{array}$ & Phase & Dir. & $\mathbf{M}$ & $\mathbf{N}$ & SD & Min & $\operatorname{Max}$ & $\mathbf{M}$ & $\mathbf{N}$ & SD & Min & Max & $\mathbf{M}$ & $\mathbf{N}$ & SD & Min & Max & M & $\mathbf{N}$ & SD & Min & $\operatorname{Max}$ \\
\hline \multirow{2}{*}{ Delhi } & Phase 1 & In & 73 & 3 & 2.20 & 72 & 76 & 71 & 2 & 0.85 & 71 & 72 & 71 & 3 & 1.85 & 69 & 72 & 79 & 3 & 2.36 & 77 & 82 \\
\hline & Phase 2 & Out & 74 & 3 & 1.44 & 72 & 75 & 74 & 2 & 0.30 & 74 & 74 & 73 & 3 & 0.44 & 73 & 74 & 79 & 3 & 1.99 & 77 & 81 \\
\hline \multirow{3}{*}{ Tokyo } & \multirow{2}{*}{ Phase 1} & Out & 73 & 3 & 1.72 & 71 & 74 & 73 & 3 & 1.57 & 72 & 74 & 72 & 3 & 1.22 & 71 & 73 & 76 & 3 & 1.83 & 74 & 78 \\
\hline & & In & 71 & 3 & 0.43 & 71 & 72 & 72 & 3 & 1.20 & 71 & 73 & 71 & 3 & 0.01 & 71 & 71 & 73 & 3 & 3.27 & 71 & 77 \\
\hline & Phase 2 & Out & 75 & 3 & 0.79 & 74 & 75 & 72 & 3 & 0.92 & 71 & 73 & 71 & 3 & 0.73 & 70 & 71 & 74 & 3 & 2.32 & 72 & 76 \\
\hline
\end{tabular}

\begin{tabular}{|c|c|c|c|c|c|c|c|c|c|c|c|c|c|c|c|c|c|c|c|c|c|c|}
\hline \multirow{2}{*}{$\begin{array}{l}\text { dB(B) } \\
\text { Dest. }\end{array}$} & \multirow{2}{*}{ Phase } & \multicolumn{6}{|c|}{ Cockpit } & \multicolumn{5}{|c|}{ Business } & \multicolumn{5}{|c|}{ Economy 1} & \multicolumn{5}{|c|}{ Economy 2} \\
\hline & & Dir. & $\mathbf{M}$ & $\mathbf{N}$ & SD & Min & $\operatorname{Max}$ & $\mathbf{M}$ & $\mathbf{N}$ & SD & Min & Max & $\mathbf{M}$ & $\mathbf{N}$ & SD & Min & $\operatorname{Max}$ & $\mathbf{M}$ & $\mathbf{N}$ & SD & Min & Max \\
\hline \multirow{4}{*}{ Delhi } & \multirow{2}{*}{ Phase 1} & Out & 74 & 3 & 3.11 & 72 & 77 & 77 & 3 & 0.47 & 76 & 77 & 79 & 3 & 1.25 & 77 & 80 & 85 & 3 & 1.23 & 83 & 86 \\
\hline & & In & 75 & 3 & 1.38 & 73 & 76 & 78 & 2 & 0.37 & 78 & 78 & 81 & 3 & 1.21 & 80 & 82 & 86 & 3 & 2.15 & 84 & 88 \\
\hline & \multirow{2}{*}{ Phase 2} & Out & 75 & 3 & 1.81 & 73 & 77 & 76 & 2 & 1.27 & 75 & 77 & 78 & 3 & 2.25 & 76 & 80 & 85 & 3 & 1.19 & 84 & 86 \\
\hline & & In & 73 & 3 & 1.42 & 72 & 74 & 75 & 2 & 1.51 & 74 & 76 & 78 & 3 & 2.06 & 76 & 80 & 84 & 3 & 3.40 & 81 & 88 \\
\hline \multirow{6}{*}{ Tokyo } & \multirow{2}{*}{ Phase 1} & Out & 74 & 3 & 1.49 & 73 & 76 & 78 & 3 & 0.68 & 77 & 78 & 79 & 3 & 0.89 & 78 & 80 & 83 & 3 & 1.90 & 81 & 85 \\
\hline & & In & 75 & 3 & 2.22 & 72 & 76 & 78 & 3 & 0.38 & 78 & 79 & 78 & 3 & 3.08 & 75 & 81 & 86 & 3 & 1.24 & 84 & 87 \\
\hline & \multirow{2}{*}{ Phase 2} & Out & 73 & 3 & 0.63 & 73 & 74 & 77 & 3 & 1.24 & 76 & 79 & 79 & 3 & 0.65 & 78 & 79 & 81 & 3 & 2.98 & 79 & 84 \\
\hline & & In & 74 & 3 & 1.71 & 72 & 76 & 78 & 3 & 0.80 & 77 & 79 & 78 & 3 & 2.98 & 74 & 80 & 86 & 3 & 1.03 & 85 & 87 \\
\hline & \multirow{2}{*}{ Phase 3} & Out & 76 & 3 & 1.36 & 75 & 78 & 76 & 3 & 0.73 & 75 & 77 & 79 & 3 & 0.93 & 78 & 80 & 81 & 3 & 2.44 & 79 & 84 \\
\hline & & In & 75 & 3 & 2.09 & 72 & 76 & 77 & 3 & 0.42 & 77 & 78 & 77 & 2 & 2.08 & 76 & 79 & 85 & 3 & 0.76 & 84 & 85 \\
\hline
\end{tabular}

reached the baseline values in post-baseline. For the time of "testing", mean HR in pilots was comparable to the HR of flight attendants during service time, but in flight attendants about $10 \mathrm{bpm}$ lower compared to service (Table 6).

\section{Heart Rate Variability}

The pNN50 of the testing time was analyzed as the mean score of three 5-min intervals and showed only on the flights to Tokyo in pilots an increase compared to baseline and postbaseline. There was no such change in flight attendants and also not on the flights to Delhi (Table 7).

\section{Blood Pressure}

Four-way ANOVA (Destination x Outgoing vs Incoming $\mathrm{x}$ Pilots $v s$ Flight attendants $\mathrm{x}$ Phase) for systolic and dia- stolic scores in blood pressure (BP) revealed no statistically significant $(\mathrm{p}>.05)$ effects. The mean values $(\mathrm{SD})$ of $\mathrm{n}=76$ measures in pilots showed a systolic BP of $\mathrm{M}=141$ (19.3) mmHG, a diastolic BP of $\mathrm{M}=90$ (11.9) $\mathrm{mmHG}$ and $\mathrm{n}=388$ measures in flight attendants showed a BP of $120 / 78$ (16.5/11.2) $\mathrm{mmHG}$.

\section{Respiration Rate}

Four-way ANOVA (Destination x Outgoing $v s$ Incoming $\mathrm{x}$ Pilots $v s$ Flight attendants $\mathrm{x}$ Phase) for respiration rate showed a main effect for Pilots vs Flight attendants $(\mathrm{F}(1$, $468)=45.81, \mathrm{p}<.001)$, for Phase $(\mathrm{F}(3,468)=4.38, \mathrm{p}<.01)$ and for Outgoing $v s$ Incoming $(\mathrm{F}(1,468)=4.56, \mathrm{p}<.01)$. Mean values indicated that flight attendants had a higher respiration rate than pilots, in both groups respiration rate 
during flight was lower than at baseline and the slowing down was more pronounced on the flight back than on the outgoing flight (Fig. 5).
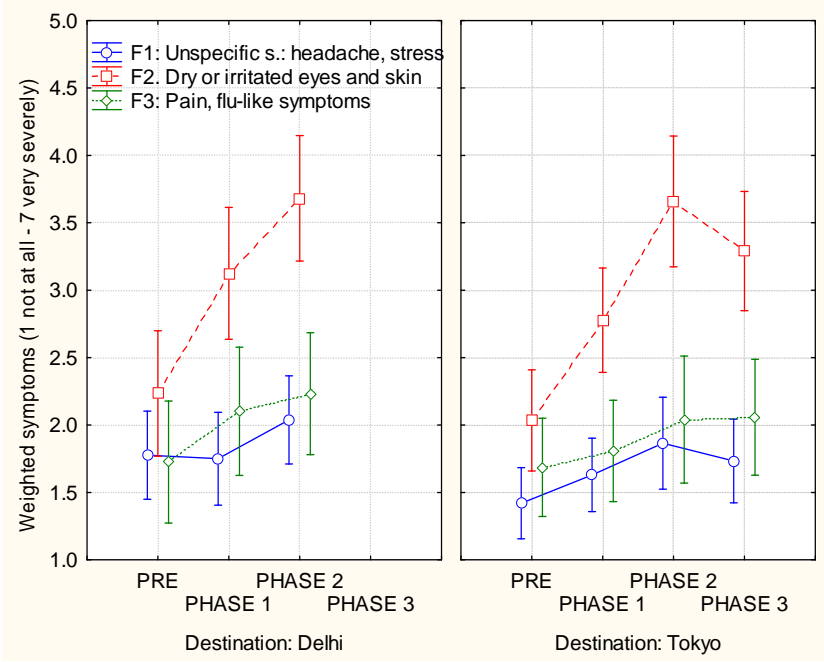

Fig. (1). Mean values and 95\% CI for the three factors of symptoms by flight destination and phase.

\section{Oxygen Saturation}

As shown in Table 8, oxygen saturation was decreasing during cruising and was lower in flight phases compared to baseline. Remarkable are single (extreme) values in pilots (with a minimum value of 89) and in flight attendants with lowest values of $90 \% \mathrm{SpO}$. To get information on the relative appearance of low values in $\mathrm{SpO} 2$ during flight conditions, percentage of occurrence of low values were computed for measurements during flights for pilots $(\mathrm{n}=52)$ and for flight attendants $(n=259)$. Values $\leq 90 \% \mathrm{SpO} 2$ were found in 1 pilot $(1.92 \%)$ and in $4(1.54 \%)$ flight attendants, values $\leq 94 \% \mathrm{SpO} 2$ were found in $26(50 \%)$ measurements of pilots and in $79(30.50 \%)$ measurements of flight attendants. The
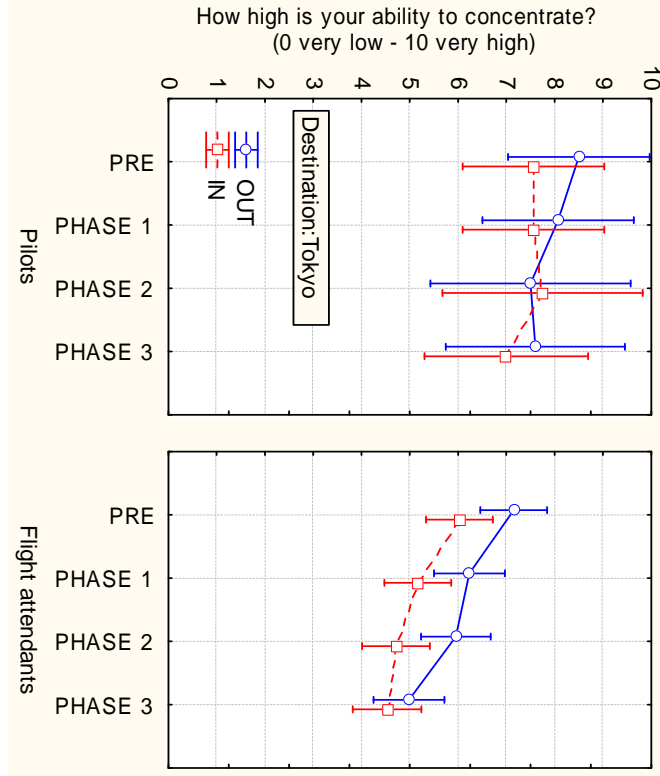
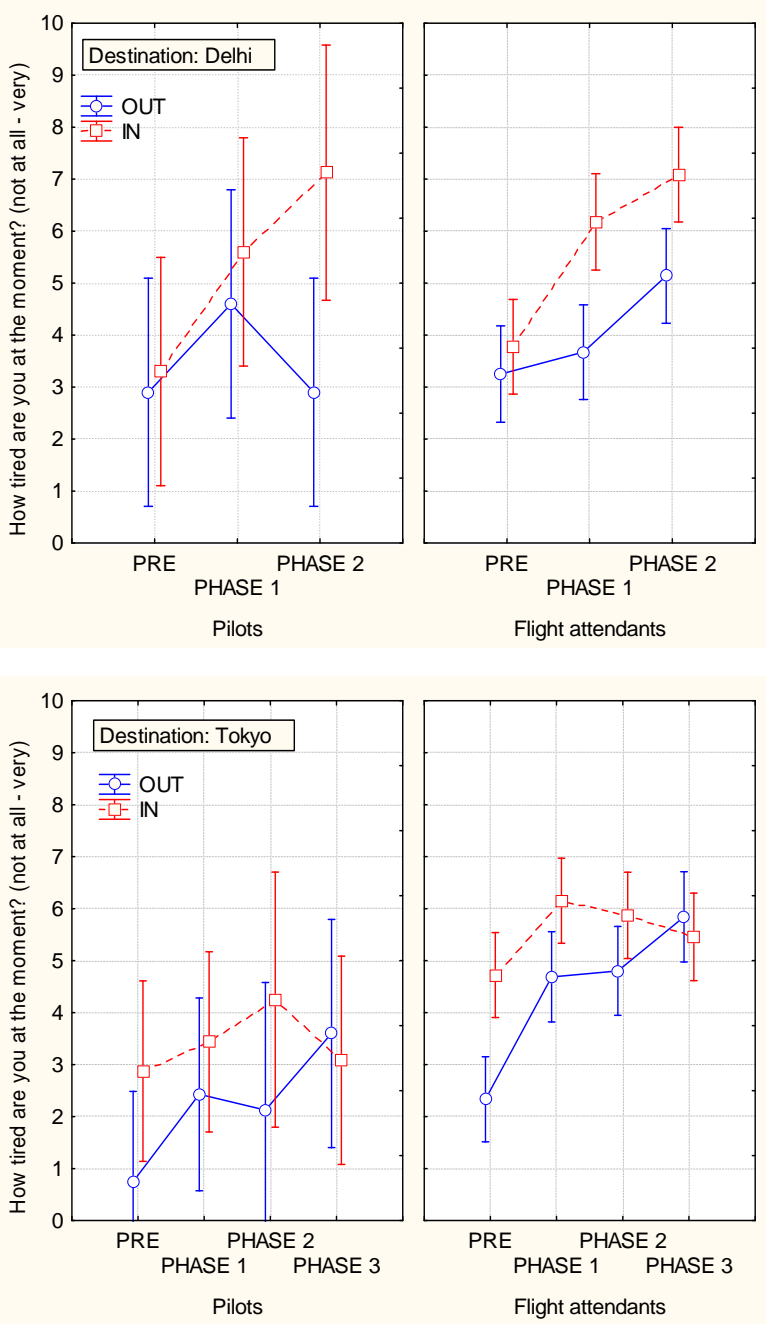

Fig. (2). Mean values and 95\% CI of ratings of tiredness for outgoing and incoming flights in pilots and flight attendants by destination (Delhi: upper part, Tokyo: lower part) and phase.
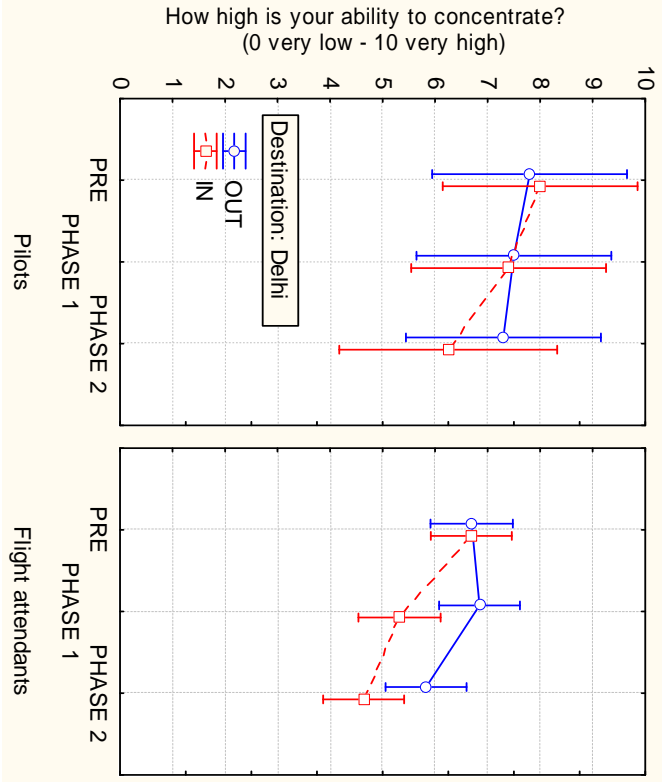

Fig. (3). Mean values and 95\% CI of rating the ability to concentrate for outgoing and incoming flights in pilots and flight attendants by destination (Delhi: upper part, Tokyo: lower part) and phase. 
Table 5. Mean Values (N, Mean-95\% CI, Mean+95\% CI, SD, Minimum and Maximum Values) of Heart Rate (bpm) for the Time of "Service of the Flight Attendants" in Pilots and Flight Attendants for Flight Destinations, Flight Phases, and Outgoing and Incoming Flights

\begin{tabular}{|c|c|c|c|c|c|c|c|c|c|c|c|c|c|c|c|c|}
\hline \multirow{2}{*}{$\frac{\text { HR serv }}{\text { Dest. }}$} & \multirow{2}{*}{ Phase } & & \multicolumn{7}{|c|}{ Pilots } & \multicolumn{7}{|c|}{ Flight Attendants } \\
\hline & & Dir. & Mean & M-CI & $\mathbf{M}+\mathbf{C I}$ & $\mathbf{N}$ & SD & Min & $\operatorname{Max}$ & Mean & M-CI & $\mathrm{M}+\mathrm{CI}$ & $\mathbf{N}$ & SD & Min & Max \\
\hline \multirow{8}{*}{ Delhi } & \multirow{2}{*}{ Pre } & Out & 78 & 67 & 88 & 5 & 8.57 & 64 & 87 & 89 & 84 & 94 & 26 & 12.48 & 67 & 109 \\
\hline & & In & 79 & 63 & 96 & 4 & 10.39 & 67 & 90 & 89 & 85 & 92 & 29 & 9.16 & 71 & 111 \\
\hline & \multirow{2}{*}{ Phase 1} & Out & 64 & 51 & 78 & 5 & 10.86 & 53 & 80 & 95 & 91 & 100 & 27 & 12.20 & 76 & 118 \\
\hline & & In & 62 & 51 & 74 & 5 & 9.18 & 52 & 74 & 94 & 90 & 99 & 29 & 12.08 & 75 & 121 \\
\hline & \multirow{2}{*}{ Phase 2} & Out & 67 & 60 & 74 & 5 & 5.48 & 62 & 76 & 98 & 94 & 103 & 27 & 10.58 & 80 & 127 \\
\hline & & In & 59 & 46 & 71 & 5 & 9.96 & 49 & 71 & 90 & 87 & 93 & 29 & 8.77 & 73 & 109 \\
\hline & \multirow{2}{*}{ Post } & Out & 74 & 58 & 91 & 5 & 13.11 & 61 & 93 & 88 & 85 & 91 & 27 & 8.46 & 77 & 108 \\
\hline & & In & 78 & 61 & 96 & 5 & 14.32 & 63 & 94 & 85 & 80 & 89 & 29 & 12.25 & 61 & 109 \\
\hline \multirow{10}{*}{ Tokyo } & \multirow{2}{*}{ Pre } & Out & 78 & 71 & 84 & 7 & 7.03 & 69 & 88 & 94 & 88 & 99 & 35 & 14.93 & 52 & 131 \\
\hline & & In & 79 & 69 & 90 & 8 & 12.90 & 57 & 93 & 82 & 78 & 86 & 35 & 11.44 & 43 & 103 \\
\hline & \multirow{2}{*}{ Phase 1} & Out & 68 & 53 & 83 & 6 & 14.12 & 50 & 89 & 105 & 100 & 111 & 30 & 15.46 & 60 & 135 \\
\hline & & In & 66 & 56 & 76 & 6 & 9.74 & 54 & 78 & 95 & 91 & 99 & 30 & 11.83 & 62 & 113 \\
\hline & \multirow{2}{*}{ Phase 2} & Out & 63 & 44 & 81 & 4 & 11.65 & 50 & 78 & 96 & 90 & 102 & 17 & 11.70 & 73 & 112 \\
\hline & & In & 63 & 38 & 88 & 5 & 19.75 & 41 & 95 & 92 & 86 & 99 & 18 & 13.04 & 58 & 111 \\
\hline & \multirow{2}{*}{ Phase 3} & Out & 68 & 54 & 83 & 4 & 9.12 & 58 & 78 & 92 & 87 & 98 & 23 & 12.71 & 69 & 117 \\
\hline & & In & 69 & 57 & 81 & 5 & 9.50 & 57 & 80 & 96 & 90 & 101 & 24 & 13.61 & 70 & 123 \\
\hline & \multirow{2}{*}{ Post } & Out & 67 & 61 & 73 & 7 & 6.68 & 56 & 74 & 83 & 80 & 86 & 35 & 9.46 & 52 & 99 \\
\hline & & In & 84 & 74 & 95 & 8 & 12.69 & 68 & 103 & 88 & 84 & 93 & 36 & 13.53 & 50 & 115 \\
\hline \multirow{5}{*}{$\begin{array}{l}\text { Delhi + } \\
\text { Tokyo }\end{array}$} & Pre & & 79 & 75 & 83 & 24 & 9.55 & 57 & 93 & 88 & 86 & 91 & 125 & 12.90 & 43 & 131 \\
\hline & Phase 1 & & 65 & 61 & 70 & 22 & 10.65 & 50 & 89 & 98 & 95 & 100 & 116 & 13.64 & 60 & 135 \\
\hline & Phase 2 & & 63 & 57 & 69 & 19 & 12.13 & 41 & 95 & 94 & 92 & 96 & 91 & 11.21 & 58 & 127 \\
\hline & Phase 3 & & 69 & 62 & 75 & 9 & 8.75 & 57 & 80 & 94 & 90 & 98 & 47 & 13.15 & 69 & 123 \\
\hline & Post & & 76 & 71 & 82 & 25 & 13.06 & 56 & 103 & 86 & 84 & 88 & 127 & 11.32 & 50 & 115 \\
\hline
\end{tabular}

relationship between blood oxygen saturation $(\mathrm{SpO} 2)$ and age was analyzed by correlations of age and $\mathrm{SpO} 2$ by flight phase including the baseline. As can be seen in Table 9, correlation analysis revealed a significant negative relationship of age with $\mathrm{SpO} 2$ in phase 1 and phase 2 (with the exception of phase 3 , in particular in flight attendants) as well as in the baseline.

\section{DISCUSSION}

Measurements of environmental conditions showed a remarkable variety in measures depending on parameter, phase, and area in the aircraft. For temperature there were deviations from a comfort temperature of about $23{ }^{\circ} \mathrm{C}-23.5$ ${ }^{\circ} \mathrm{C}$ not only in the measured minimum $\left(18.5^{\circ} \mathrm{C}\right)$ and maximum $\left(27.7^{\circ} \mathrm{C}\right)$ values, but also for mean values and without any obvious systematic relationship. Air humidity was lowest in the cockpit, with the lowest values of $0 \% \mathrm{RH}$ and maximum values of $8 \% \mathrm{RH}$, low in the business section and highest in the rear of the economy section with up to $18 \%$ $\mathrm{RH}$. Sound pressure level was lowest in the cockpit and highest in the rear of the economy section (up to mean SPL of $79 \mathrm{~dB}$ ) for the A-weighted SPL, the same pattern was found for B-weighted SPL, however, the difference was more pronounced in the latter, indicating a higher level of SP with lower frequencies in the rear of the aircraft.

Ratings indicate an increase of symptoms during flight compared to baseline. Although that pattern was found in all 3 factors of symptoms as are "unspecific symptoms" (headache, stress, etc.), pain and flu-like symptoms, and dry or irritated eyes and skin, the latter showed a much higher change by time as the others. Irritations of eyes and skin were also reported by Lindgren, Andersson, Dammström, \& Norbäck [13] as the most common symptoms (besides fatigue) among aircrew, however, data were collected by using mailed questionnaires from people working in a Scandinavian flight company, and were not rated during specific phases on flights.

In the present study, ratings of tiredness indicated a general increase by time, a higher tiredness on the flight back from Delhi (in both pilots and flight attendants), whereas on the flights to Tokyo no differences were observed for arriving at the destination, but baseline measures were different 
Table 6. Mean Values (N, Mean-95\% CI, Mean+95\% CI, SD, Minimum and Maximum Values) of Heart Rate (bpm) During Questionnaire Epoch in Pilots and Flight Attendants for Flight Destinations, Flight Phases, and Outgoing and Incoming Flights

\begin{tabular}{|c|c|c|c|c|c|c|c|c|c|c|c|c|c|c|c|c|}
\hline $\begin{array}{c}\text { HR qu } \\
\text { Dest. }\end{array}$ & Phase & Dir. & Mean & M-CI & $\mathbf{M}+\mathbf{C I}$ & $\mathbf{N}$ & SD & Min & $\operatorname{Max}$ & Mean & M-CI & $\mathbf{M}+\mathbf{C I}$ & $\mathbf{N}$ & SD & Min & Max \\
\hline \multirow{5}{*}{ Delhi } & Pre & In & 79 & 63 & 96 & 4 & 10.39 & 67 & 90 & 89 & 85 & 92 & 29 & 9.16 & 71 & 111 \\
\hline & Phase 1 & Out & 66 & 58 & 75 & 5 & 7.03 & 61 & 78 & 87 & 83 & 91 & 27 & 9.30 & 70 & 106 \\
\hline & Phase 2 & In & 62 & 54 & 71 & 5 & 6.83 & 56 & 72 & 79 & 75 & 83 & 29 & 10.00 & 63 & 102 \\
\hline & \multirow{2}{*}{ Post } & Out & 74 & 58 & 91 & 5 & 13.11 & 61 & 93 & 88 & 85 & 91 & 27 & 8.46 & 77 & 108 \\
\hline & & In & 78 & 61 & 96 & 5 & 14.32 & 63 & 94 & 85 & 80 & 89 & 29 & 12.25 & 61 & 109 \\
\hline \multirow{7}{*}{ Tokyo } & Pre & Out & 78 & 71 & 84 & 7 & 7.03 & 69 & 88 & 94 & 88 & 99 & 35 & 14.93 & 52 & 131 \\
\hline & \multirow{2}{*}{ Phase 2} & Out & 59 & 39 & 80 & 4 & 13.00 & 43 & 74 & 84 & 77 & 91 & 18 & 13.93 & 48 & 107 \\
\hline & & In & 62 & 45 & 80 & 5 & 14.10 & 46 & 82 & 81 & 75 & 87 & 18 & 12.18 & 53 & 102 \\
\hline & \multirow{2}{*}{ Phase 3} & Out & 68 & 54 & 81 & 4 & 8.45 & 60 & 78 & 82 & 77 & 86 & 23 & 11.07 & 60 & 99 \\
\hline & & In & 68 & 49 & 88 & 5 & 16.04 & 50 & 89 & 81 & 76 & 86 & 24 & 11.50 & 62 & 109 \\
\hline & \multirow{2}{*}{ Post } & Out & 67 & 61 & 73 & 7 & 6.68 & 56 & 74 & 83 & 80 & 86 & 35 & 9.46 & 52 & 99 \\
\hline & & In & 84 & 74 & 95 & 8 & 12.69 & 68 & 103 & 88 & 84 & 93 & 36 & 13.53 & 50 & 115 \\
\hline \multirow{4}{*}{$\begin{array}{c}\text { Delhi + } \\
\text { Tokyo }\end{array}$} & Pre & & 79 & 75 & 83 & 24 & 9.55 & 57 & 93 & 88 & 86 & 91 & 125 & 12.90 & 43 & 131 \\
\hline & Phase 1 & & 66 & 62 & 70 & 22 & 8.63 & 48 & 78 & 85 & 83 & 88 & 116 & 11.87 & 54 & 126 \\
\hline & Phase 2 & & 63 & 58 & 68 & 19 & 10.15 & 43 & 82 & 83 & 81 & 86 & 92 & 12.13 & 48 & 111 \\
\hline & Phase 3 & & 68 & 58 & 78 & 9 & 12.48 & 50 & 89 & 81 & 78 & 85 & 47 & 11.18 & 60 & 109 \\
\hline
\end{tabular}

for in- and outgoing flights in pilots and flight attendants, which may indicate effects of jetlag. The remarkably higher scores of tiredness in pilots on the Delhi flights as opposed to the Tokyo flights are comparable to the pattern of the pNN50, a measure of heart rate variability, with a lower pNN50 in pilots on the flights to Delhi compared to the flights to Tokyo. Moreover, a comparable pNN50 in flight attendants on the flights to Delhi contrary to the flights to Tokyo, where pilots had a remarkably higher pNN50 than flight attendants, suggests that low values in pNN50 that are a physiological indication of a highly sympathetic activity in the autonomic nervous system may be associated with tiredness at least for long-term conditions in the airplane. The generally higher levels of tiredness on the incoming flights support the findings of Samel, Wegmann, Vejvoda, Drescher, Gundel, Manzey, \& Wenzel [14] and of Samel, Wegmann, Vejvoda, \& Wittiber [15], reporting that fatigue was more pronounced on return flights. As an underlying mechanism, besides load from jet lag [16], the lower quality of resting away from home compared to resting at home [17] can be considered.

For the physiological response of the cardiovascular system as measured by HR, differences were found between pilots and flight attendants. Whereas HR in pilots decreased

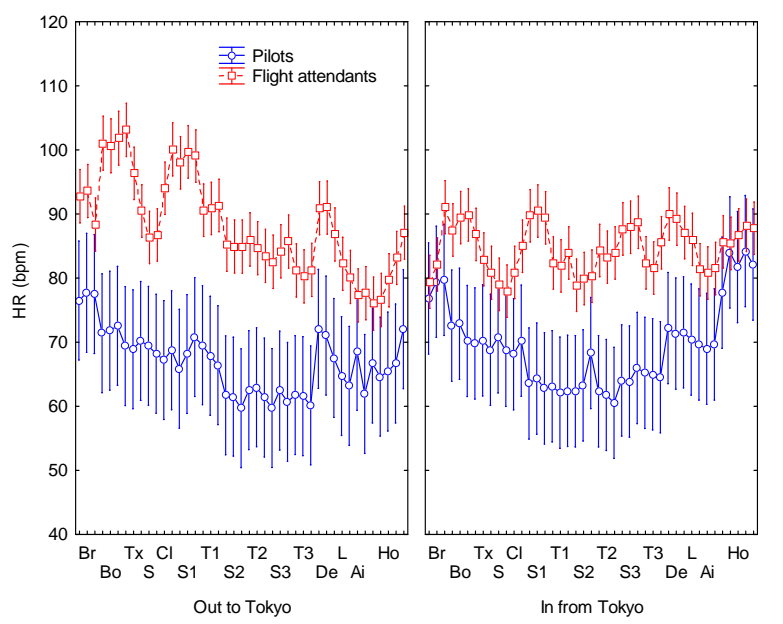

Fig. (4). Mean and 95\% CI of heart rate (HR) in pilots and flight attendants averaged across (non-sleeping) persons of 3 flights from Vienna to Tokyo (Out) and back (In). Three 5-min intervals are presented for briefing (Br), boarding (Bo), taxiing (Tx), one 5-min interval for start (S), three 5-min intervals for climbing $(\mathrm{Cl})$, first service (S1), first test phase (T1), second service (S2), second test phase (T2), third service (S3), third test phase (T3), descending (De), one 5-min interval for landing (L), three 5-min intervals for being on the airport, and five 5-min intervals for the way to and debriefing in the hotel or debriefing at Vienna airport respectively (Ho). 
Table 7. Mean Values (N, Mean-95\% CI, Mean+95\% CI, SD, Minimum and Maximum Values) of pNN50 (\%/100) During Questionnaire Epoch in Pilots and Flight Attendants for Flight Destinations, Flight Phases, and Outgoing and Incoming Flights

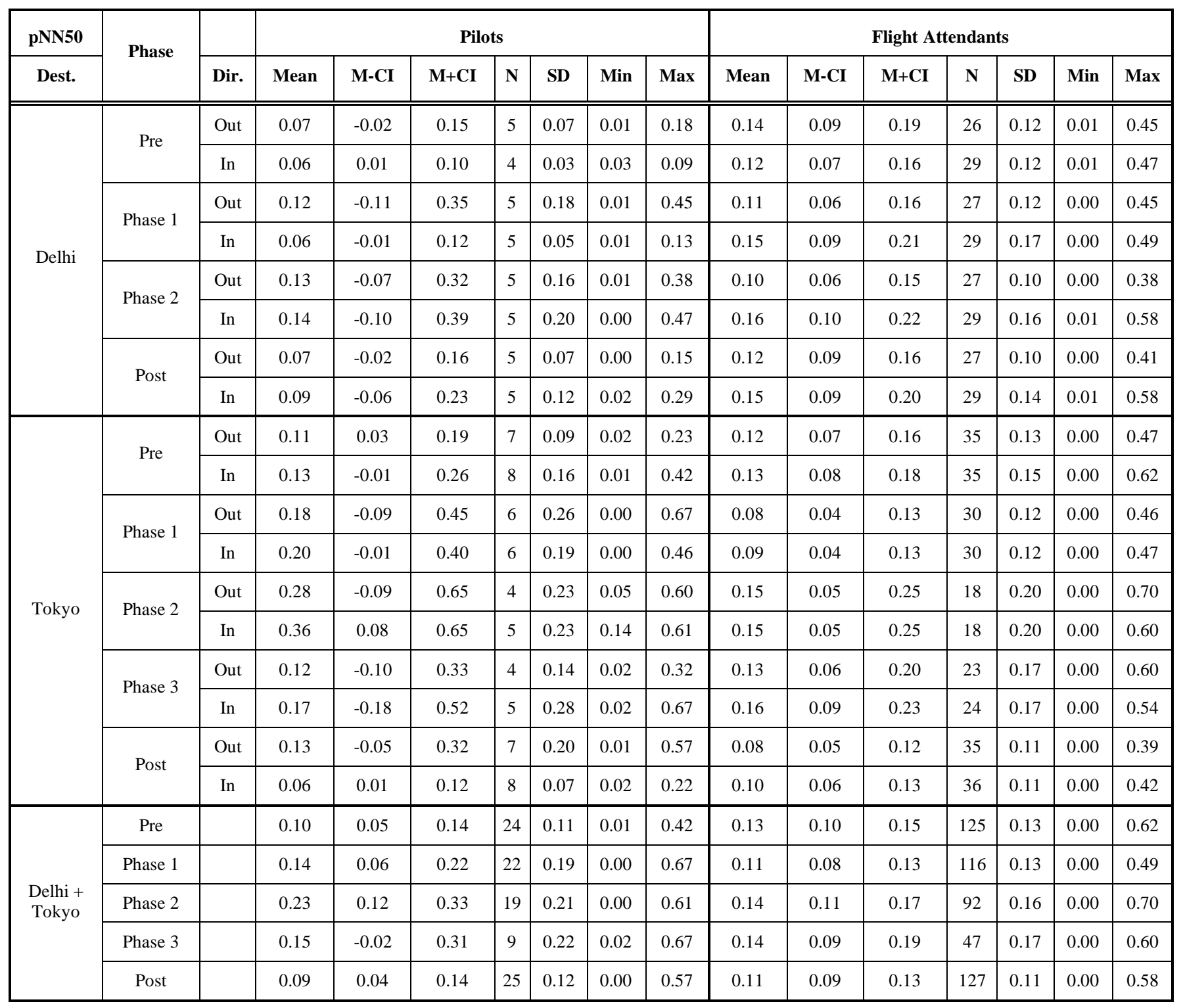

during flight (with a relative increase at the time of initiating the descent, as also reported by Lee \& Liu [18]) and increased at the target airport and the hotel, in flight attendants a high HR was found for the time of boarding, time of the services, and also for the time of clearing up the galley during the time of descending. Whereas flight attendants showed relatively high HR up to maximum values of 135 bpm, low values were observed in pilots with a minimum HR of $41 \mathrm{bpm}$, as also reported elsewhere [19]. A remarkable slowing down of the respiration rate was also observed in pilots during cruising. Low activation states in pilots were already reported by recording the electric activity of the brain (electroencephalogram) and eye movements [20, 21]. As a consequence of such low activation states associated with tiredness and sleepiness, the development of alertness devices was initiated and their function was proven [22].

Heart rate variability, as measured by pNN50 reflecting vagal stimulation [12], indicated low parasympathetic activ- ity in pilots and flight attendants on the Delhi-flights and in flight attendants also on the Tokyo-flights, however, not in pilots on the Tokyo route. This indicates (1) a remarkable load in most of the flights (as also noted by MacDonald, Deddens, Grajewski, Whelan, \& Hurrell [23]) and (2) a reduced load for the 3-pilots-crew on the flights to Tokyo only; however, pilots as well as flight attendants had a 3-hour resting period during flight, but higher pNN50 values were evident only in pilots, for which other factors may be crucial; during flights, in colloquial conversations, pilots mentioned that the flight to Delhi is somewhat peculiar as they fly over the Middle East and the border between Pakistan and India, that area being not as quiet as, e.g., the route over the north pole. Thus one may speculate that the higher pNN50 values in pilots to Tokyo may reflect the response of a 3-pilots-crew on a long-haul flight, the relatively low pNN50 values in flight attendants may be related to task demands, and the low values in pilots to Delhi may correspond to characteristics of 
Table 8. Mean Values (N, Mean-95\% CI, Mean+95\% CI, SD, Minimum and Maximum Values) of Oxygen Saturation in Blood (\%Sp02) During Questionnaire Epoch in Pilots and Flight Attendants for Flight Destinations, Flight Phases, and Outgoing and Incoming Flights

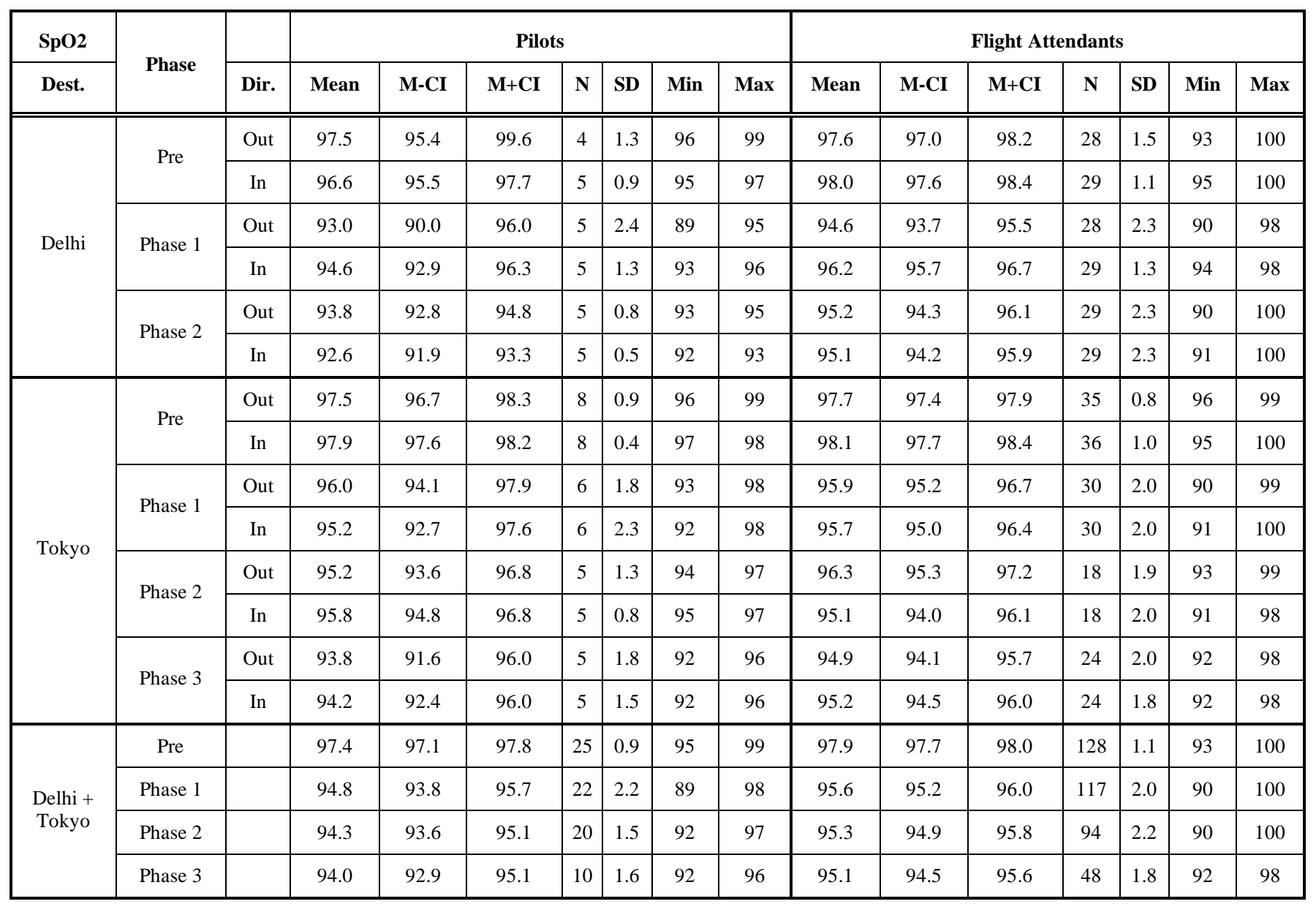

the flight route. Although pilots have a low heart rate during cruising, this cannot be interpreted as having no load. To fulfill the task demands under low activation states (as also reported by Wright \& McGown [20,21]) is a source of stress like the interior noise $[24,25]$. In particular noise, even in moderate intensity, is a source of stress and affects besides health and well-being also performance [26]. These aspects may be of relevance for the relatively high scores in systolic and diastolic blood pressure, as found in pilots.

Effects of stress are, at least, threefold: (1) health impairment indicated by higher scores in health problems as found in cabin attendants [27], or effects on the immune system (immunoglobulin) in air force aviators [28], (2) mood and well-being impairment (e.g., low self-esteem and high frustration in cabin attendants [27]), (3) and implications on human error. Concerning human error, it was also shown that stress - in particular if associated with tiredness - shows a significant relationship with air incidents as found by Loewenthal, Eysenck, Harris, Lubitsh, Gorton, \& Bicknell [29] and has therefore far-reaching implications on air safety. Implications of stress on air safety were also pointed out by Samel, Vejvoda, \& Maass [30], stating that accumulated sleep deficit - although found in another operation setting of pilots - may induce stress and lead to incomplete recuperation.
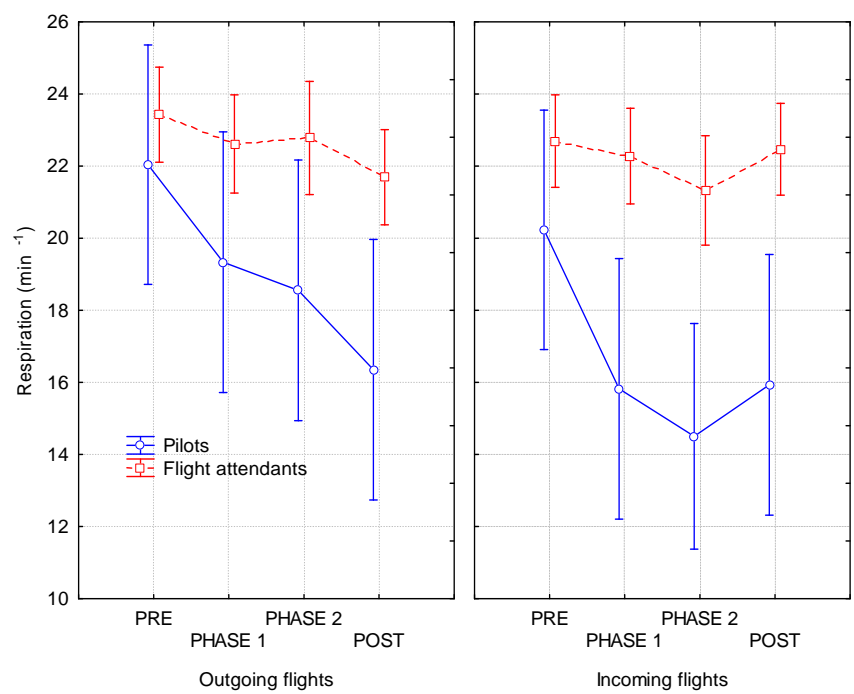

Fig. (5). Mean and $95 \% \mathrm{CI}$ of respiration rate in pilots and flights attendants on outgoing and incoming flights and for phase.

Besides environmental stress, occupational stress, and stress coming from task demand, low blood oxygen saturation is discussed as a possible source of impaired well-being [31], affecting performance, at least in athletes [32]; furthermore, it is discussed as an issue of health impairment [5]. 
In the present study about $2 \%$ of in-flight measures displayed a score of $\leq 90 \% \mathrm{SpO} 2,31 \%$ of flight attendants and $50 \%$ of pilots had in-flight measures of $\leq 94 \% \mathrm{SpO}$. The critical question about the limit of harmfulness is currently discussed as a normal physiological response [33] or as an issue of intervention, as it is done in a clinical setting in persons with $\mathrm{SpO} 2 \leq 94 \%$ [5].

Table 9. Correlations Coefficients of the Correlation Between Age and $\mathrm{SpO2}$ in Pilots and Flight Attendants for Baseline and Flight Phase

\begin{tabular}{|c|c|c|c|c|}
\hline $\begin{array}{c}\text { Correlations Between } \\
\text { Age and } \mathrm{SpO}_{2}\end{array}$ & \multicolumn{2}{|c|}{ Pilots } & \multicolumn{2}{c|}{$\begin{array}{c}\text { Flight } \\
\text { Attendants }\end{array}$} \\
\hline Phase & $\mathbf{n}$ & $\mathbf{r}$ & $\mathbf{n}$ & $\mathbf{r}$ \\
\hline \hline Baseline & 25 & $-.44^{*}$ & 126 & $-.31^{* * *}$ \\
\hline Phase 1 & 25 & $-.38^{+}$ & 127 & $-.31^{* * *}$ \\
\hline Phase 2 & 22 & $-.36^{+}$ & 128 & $-.38^{* * *}$ \\
\hline Phase 3 & 11 & -.33 & 72 & -.18 \\
\hline Phase $1+2+3$ & 58 & $-.34 * *$ & 327 & $-.30^{* * *}$ \\
\hline
\end{tabular}

There are some limitations of the study. One limitation is the restriction to interpret effects of environment in a causal way. As there is always a number of causes (i.e., nonoptimal conditions causing physiological or psychological stress) interacting simultaneously, only the "combined effect" of environmental conditions and task load (including aspects of time on task) could be quantified. On the other hand, this setting has a high value with reference to external validity. Another restriction raised is the limited number of investigated persons, in particular only 13 pilots (although each on 2 flights) were investigated. However, the majority of studies, in particular with physiological in-flight measurements, was conducted with a comparable sample size [20, 34]. Although it is obvious that there are limitations in generalizing single values or values based on a sample size of 3 persons in specific conditions, boundary values are still illustrating real values as they may appear in the field, as in the case of (single) low values in blood oxygen saturation $(\mathrm{SpO} 2)$; and it was also demonstrated that such values are "not only" outliers, but follow the rule that oxygen saturation decreases with age.

The present study was undertaken as a field investigation. This has the advantage of high external validity and, indeed, remarkable differences in the human response were found compared to an experimental laboratory study, which was also part of the project HEACE. Without going into details, the response in the field study revealed a higher load and a greater variety of the response than the response in the laboratory study, which was, however, undertaken with air pressure of ground level [35]. Thus, differences in human response from laboratory study to real flights may be caused by the impact of low air pressure and/or by the fact that a real flight may cause additional load. On the other hand, as the systematic variation of environmental conditions in real flights is very limited, it seems necessary, e.g., for modeling the impact of environmental conditions on comfort or performance [36], to conduct laboratory experiments.

Taken together, results of the present study showed a relatively high variation in all parameters, which were associated with flight destination, flight duration, outgoing vs incoming flights, and the area within the aircraft as well as associated with task demands as reflected by the comparison of pilots and flight attendants. This suggests that single mean values may reflect only to a very limited extent physical environmental conditions and the human response of pilots and flight attendants in real flights on commercial aircraft.

\section{ACKNOWLEDGEMENT}

This investigation was part of the project HEACE ('Health Effects of Cabin Environment'), funded by the European Community under the 'Competitive and Sustainable Growth' Program, 6th Framework, Project No. GRD12001-40118, co-ordinated by Prof. Dr. Volker Mellert, University of Oldenburg. Partners involved were Medical University Vienna (Elisabeth Groll-Knapp, Michael Trimmel, Christoph Goger, Medical University of Vienna, OE Public Health, Institute for Environmental Hygiene, Kinderspitalgasse 15, A-1095 Vienna, Austria); University of Oldenburg (Volker Mellert, Ingo Baumann, Nils Freese, Reinhard Weber, Carl-von-Ossietzky University of Oldenburg, Department of Physics, Carl-von-Ossietzky Str. 9-11, D-26129 Oldenburg, Germany); ITAP GmbH (Michael Bellmann, Herrmann Remmers, ITAP GmbH, Institute of Technical and Applied Physics, D-26129 Oldenburg, Germany); EADS-CRC (Michael Grünewald, Peter Faulhaber, Arno Röder, EADS, European Aeronautic Defence and Space Company, CRC Germany, D-81663 Munich, Germany); BRE (John Seller, Claire Aizlewood, Helen Emms, Lorna Hamilton, BRE; Garston, Watford WD25 9XX, UK); Demos Tsahalis, University of Patras, Chemical Engineering Department, G-26500 Patras, GREECE; PARAGON LTD, Athens, GREECE; Cira (Italien Aerospace Research Centre), Napoli, IT.

\section{REFERENCES}

[1] Committee on Air Quality in Passenger Cabins of Commercial Aircraft. The airliner cabin environment and the health of passengers and crew. Washington, DC: The National Academies Press; 2002.

[2] Rayman RB. Passenger safety, health, and comfort: A review. Aviat Space Environ Med 1997; 68: 432-40.

[3] Ballard T, Corradi L, Lauria L, et al. Integrating qualitative methods into occupational health research: A study of women flight attendants. J Occup Environ Med 2004; 61: 163-6.

[4] Sharma L. Lifestyles, flying and associated health problems in flight attendants. J R Soc Promot Health 2007; 127: 268-75.

[5] Humphreys S, Deyermond R, Bali I, Stevenson M, Fee J. The effect of high altitude commercial air travel on oxygen saturation. Anaesthesia 2005; 60: 458-60.

[6] Muhm J, Rock P, McMullin D, et al. Effect of aircraft-cabin altitude on passenger discomfort. N Engl J Med 2007; 357: 18-27.

[7] Lindgren T, Andersson K, Norbäck D. Perception of cockpit environment among pilots on commercial aircraft. Aviat Space Environ Med 2006; 77: 832-7.

[8] Lindgren T, Norbäck D, Andersson K, Dammström B. Cabin environment and perception of cabin air quality among commercial aircrew. Aviat Space Environ Med 2000; 71: 774-82.

[9] Jennings J, McKnight J. Inferring vagal tone from heart rate variability. Psychosom Med 1994; 56: 194-6. 
[10] Mulder L. Measurement and analysis methods of heart rate and respiration for use in applied environments. Biol Psychol 1992; 34: 205-36.

[11] Trimmel M, Wright N, Backs RW. Psychophysiology in ergonomics: Preface to the special section. Hum Factors 2003; 45: 523-4.

[12] No Authors Listed. Heart rate variability. Standards of measurement, physiological interpretation, and clinical use. Task force of the european society of cardiology and the north american society of pacing and electrophysiology. Eur Heart J 1996; 17: 354-81.

[13] Lindgren T, Andersson K, Dammström B, Norbäck D. Ocular, nasal, dermal and general symptoms among commercial airline crews. Int Arch Occup Environ Health 2002; 75: 475-83.

[14] Samel A, Wegmann H, Vejvoda M, Drescher J, Gundel A, Manzey D, Wenzel J. Two-crew operations: Stress and fatigue during longhaul night flights. Aviat Space Environ Med 1997; 68: 679-87.

[15] Samel A, Wegmann H, Vejvoda M, Wittiber K. Stress and fatigue in long distance 2-man cockpit crew. Wien Med Wochenschr 1996; 146: $272-6$.

[16] Spillane R, Bassett J. "Jet lag" as an occupational stressor. In: McConkey K, Wilton H, Barnier A, Bennett A Eds. Australian psychology: Selected applications and initiatives. Australia: Carlton South VIC 1994; pp. 61-8.

[17] Cooper C, Sloan S. Coping with pilot stress: Resting at home compared with resting away from home. Aviat Space Environ Med 1987; 58: 1175-82.

[18] Lee Y, Liu B. Inflight workload assessment: Comparison of subjective and physiological measurements. Aviat Space Environ Med 2003; 74: 1078-84.

[19] Trimmel M, Goger C, Vouk E, Kritz M, Klaus A, Groll-Knapp E. Heart rate of pilots during long haul flights indicate low arousal states. Psychophysiology 2005; 42: $26 \mathrm{~S}$

[20] Wright N, McGown A. Involuntary sleep during civil air operations: Wrist activity and the prevention of sleep. Aviat Space Environ Med 2004; 75: 37-45.

[21] Wright N, McGown A. Vigilance on the civil flight deck: Incidence of sleepiness and sleep during long-haul flights and associated changes in physiological parameters. Ergonomics 2001; 44: 82106.

[22] Wright N, Powell D, McGown A, Broadbent E, Loft P. Avoiding involuntary sleep during civil air operations. Validation of a wristworn alertness device. Aviat Space Environ Med 2005; 76: 847-56.

[23] MacDonald L, Deddens J, Grajewski B, Whelan E, Hurrell J. Job stress among female flight attendants. J Occup Environ Med 2003; 45: 703-14.
[24] Mellert V, Weber R. Application of vibro-acoustic and psychoacoustic protocols for the evaluation of interior noise in the aircraft cabin: 19th International Congress on Acoustics, Madrid; 2007.

[25] Mellert V, Weber R, Buss S, Baumann I, Freese N, Bellmann M Noise at work 2007/72. Impact of noise and vibration on flight and cabin crew. Impact du bruit et des vibrations sur les personnels avigants, 2007, available from https://intellagence.eu.com/bin/pdfabs tract?dir=noiseatwork2007\&ref=72 [retrieved 2008 Jan 21].

[26] Trimmel M, Poelzl G. Impact of background noise on reaction time and brain de potential changes of vdt-based spatial attention. Ergonomics 2006; 49: 202-8

[27] Barnes B. Stress in aviation personnel. Psychol Stud 1992; 37: 1-6.

[28] Vaernes R, Myhre G, Aas H, Homnes T, Hansen I, Tonder O. Relationships between stress, psychological-factors, health, and immune levels among military aviators. Work Stress 1991; 5: 5-16.

[29] Loewenthal K, Eysenck M, Harris D, Lubitsh G, Gorton T, Bicknell H. Stress, distress and air traffic incidents: Job dysfunction and distress in airline pilots in relation to contextually-assessed stress. Stress Med 2000; 16: 179-83.

[30] Samel A, Vejvoda M, Maass H. Sleep deficit and stress hormones in helicopter pilots on 7-day duty for emergency medical services. Aviat Space Environ Med 2004; 75: 935-40.

[31] Hinninghofen H, Enck P. Passenger well-being in airplanes. Auton Neurosci 2006; 129: 80-5.

[32] Geertsema C, Williams A, Dzendrowskyj P, Hanna C. Effect of commercial airline travel on oxygen saturation in athletes. $\mathrm{Br} \mathrm{J}$ Sports Med 2007; 42: 577-81.

[33] Bagshaw M. A response to 'the effect of high altitude commercial air travel on oxygen saturation'. Anaesthesia 2005; 60: 948 .

[34] Faerevik H, Reinertsen R. Effects of wearing aircrew protective clothing on physiological and cognitive responses under various ambient conditions. Ergonomics 2003;46: 780-799.

[35] Trimmel M, Goger C, Groll-Knapp E, et al. Modeling the impact of envionmental conditions on comfort, task load and motivation in the mock up and in real flights: Proceedings 1st IC-EpsMso, Athens; 2005.

[36] Bellmann M, Remmers H, Röder A. Environmental conditions for cockpit and cabin crew members during long-haul flights. From experimental results to a representative vibro-acoustic input vector for ann and statistical approaches: 33rd German Annual Conference on Acoustics, Stuttgart; 2007.

(C) Michael Trimmel; Licensee Bentham Open.

This is an open access article licensed under the terms of the Creative Commons Attribution Non-Commercial License (http://creativecommons.org/licenses/by$\mathrm{nc} / 3.0 /$ ) which permits unrestricted, non-commercial use, distribution and reproduction in any medium, provided the work is properly cited. 